\title{
PC Based LCD Scrolling Message Display using GSM Modem
}

\author{
Mahesh Kodak ${ }^{1}$, Komal-Vishal Pandharkar ${ }^{2}$, Sagar Kadam $^{3}$, Amol Bandal ${ }^{4}$ \\ Department of Computer Engineering, Sinhgad Institute of Technology Lonavala ${ }^{1,2,3,4}$
}

\begin{abstract}
Displaying information is an important part in day to day life, so that we are trying to display the message through the LCD in every area and the message will be send through the mobile phones and the priority base information can be displayed on the LCD screen. The authentication purpose we are using the GSM technology which improves security in displaying message. A hi-tech wireless display board use for displaying anywhere. The project is built around the AT89C51 micro controller from Atmel.
\end{abstract}

Keywords: Global System for Mobile (GSM), SMS, PC, LCD, AT 80c51

\section{INTRODUCTION}

Our India is the developing country, and it is rolling display.This system is also importance mainly for introducing towards the wireless communication network police or army i.e. displays will be connected to all the which play importance in daily life. Today's world is so main centres in city if they want to display messages about much fast and technical it having importance to get the something enemy attack then within 2-5 minute, which message for the communication and getting information to they can get the information in every police station. So each and every person, so that it can work according to keeping this in mind a new display system which can be the given message. In this project we are going to display accessed remotely, using the GSM technology to make the the important notices, information etc.to communicate communication between microcontroller and mobile was with the public areas. The use of "Embedded System designed.

Communication" has given rise to many interesting applications that ensures comfort and safety to human life. The project provides us with easy and user friendly interface to display any message on the LCD Screen. There is no need to manually write the message like in conventional display boards thus it is more popular.

\section{RELATED WORK}

We are seen this type of Project many times in daily life like Railway platform, Hospitals, Educational institutes, Many types of markets etc. but they are not like priority base but they are connected with cable through the $\mathrm{PC}$ which having physical connection which is not suitable for long distance area. So we decided that wireless communication for displaying the message on the LCD. Previously there were LED Matrix are used to Display the notice but for user friendly we propose to use the Liquid crystal Display which having high flexibility .

\section{BLOCK DIAGRAM}

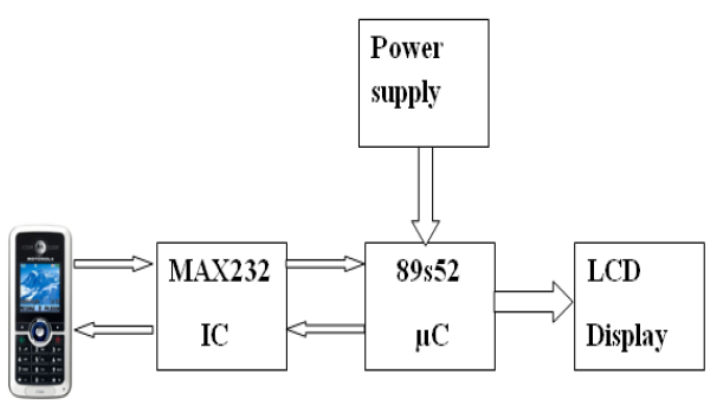

Now a days everything will be a digitally display in the shops, markets and Railway station but they are using
The Atmel AT89C51 microcontroller is used for the main purpose of giving final output to the LCD Screen. As the memory capacity of this micro Controller is limited, it is memory interfaced with a sufficient capacity EEPROM IC to fetch the decoding codes for the alphabets, numerical and special symbols. Use of LCD provides many advantages like low cost, high brightness, low power consumption, ease of maintenance, easily available etc.

\section{MAIN FUNCTION OF GSM BASED SMS DRIVEN TO DISPLAY ON LCD}

This project use to provides more useful because which display the information according to our priority of the data. The Controller are given the priority to display the information with security because each and every GSM having different number and they are unique in nature.

They are most efficiently used in our life for communicating with each other and they provide more security in the communication.

1. Using GSM mobile we can send message to any distant located e-notice board from any GSM service area.

2. By interfacing the GSM modem with authenticated user, we can send text message from any GSM area.

3. GSM MODEM, SIM, LCD (Liquid Crystal Display), microcontroller, power supply and also some connecting wires are the common things required for developing any GSM based application. 


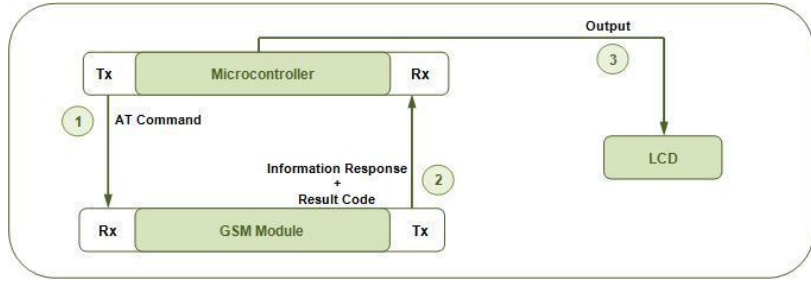

Fig: Controlling Action By GSM

In this controlling action taken by controller through the GSM module, information response with result code given to the controller which take an action and message will be display on LCD screen.

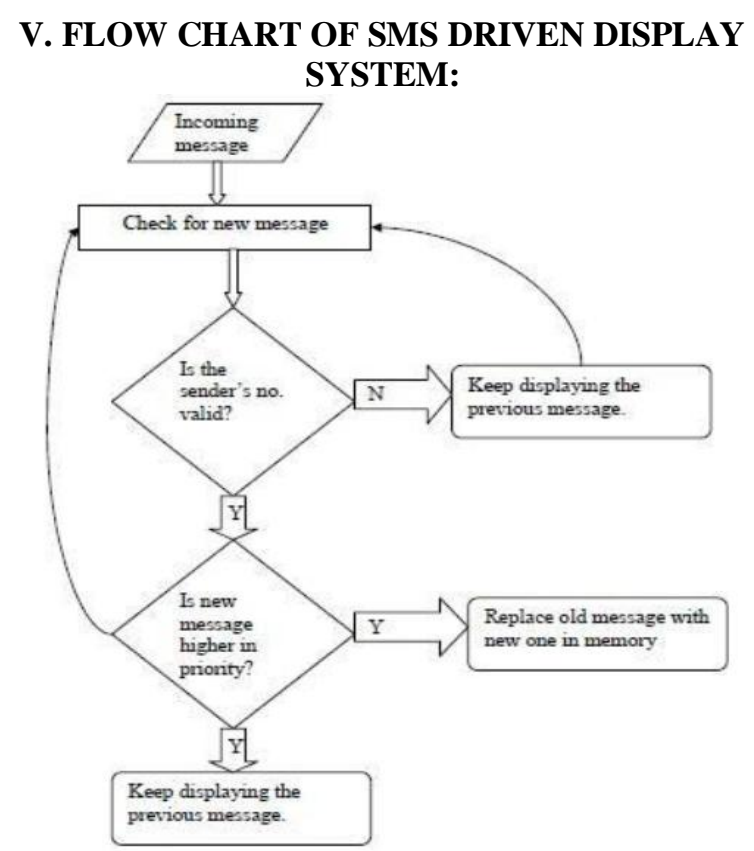

The flow chart shows that the controlling action taken by GSM and sender valid number checks if it's not right then the previous message will be display for some time,then message will be change when message will change and the message are given an according to the priority message will be display. If given message will be changes with message send given according to priority.

\section{A) GSM MODEM USED TO CONTROL:}

This GSM Modem can accept any GSM network operator SIM card and act justlike a mobile phone with its own unique phone number.

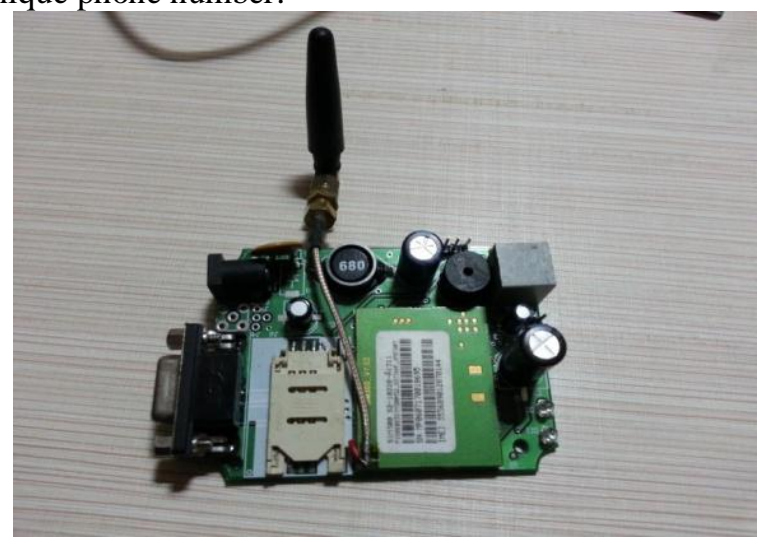

A GSM modem is a wireless modem that works with a GSM wireless network. A wireless modem behaves like a dial-up modem. The main difference between them is that a dial-up modem sends and receives data through a fixed telephone line while a wireless modem sends and receives data through radio waves. Like a GSM mobile phone, a GSM modem requires a SIM card from a wireless carrier in order to operate.

\section{B) LCD USED FOR DISPLAY:}

One of the most common devices attached to an 8051 is an LCD display. Here we have used 16x2- that means 2 rows and 16 characters.

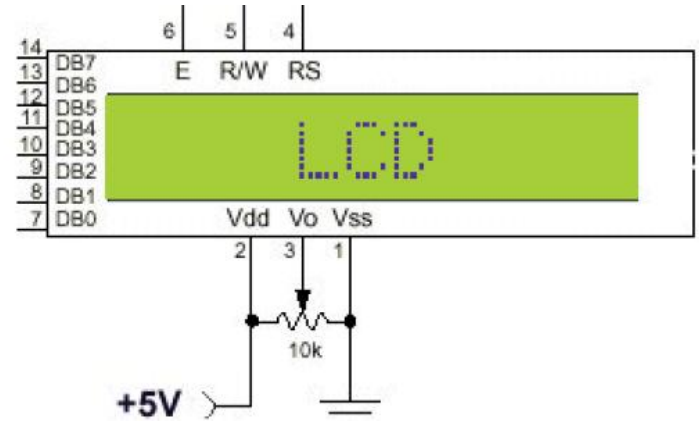

LCD display is used for simulation purpose. While implementation this can be replaced by actually displayboards.

Pin 4 - This is RS i.e. register select pin.

Pin 5 - This is R/W i.e. Read/Write pin.

Pin 6 - This is E i.e. Enable pin.

Pin $2-$ This is VDD i.e. power supply pin.

C) MICROCNTROLLER FOR PROCESSING:

Microcontroller are used to take an action on the signal receiving through the GSM,Microcontroller - specially designed for performing single task, is a computer-on-achip usually comprises of I/O ports, RAM, ROM and also CPU. Due to simplicity in design and pocket friendly prices, microcontroller is widely adopted for various fields including automobiles, medical science, defence, domestic applications, industrial use, energy management and lots more domains.

The high-performance CMOS 8-bit microcomputer with $8 \mathrm{~K}$ bytes of Flash programmable and erasable read only memory (PEROM).

\section{V.COMPARISION OF GSM Vs BLUETOOTH}

The following diagram contain rough comparison between different wireless technologies. It is conceptual in nature.

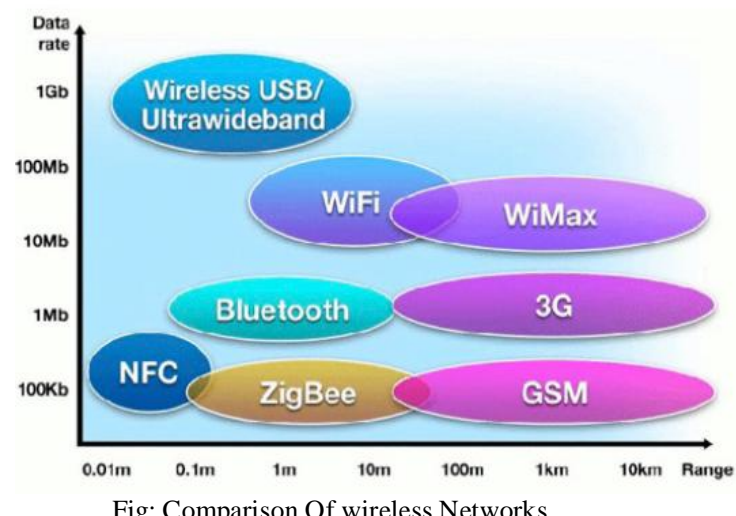

Fig: Comparison Of wireless Networks 
From the above graph we can compare the GSM with various wireless communication networks but in all that the GSM having very much compactable with very high security.

GSM used world-wide with very high speed and maximum area will be cover through the GSM which having a maximum Range to cover.

\section{APPLICATION}

- Colleges: for displaying important messages. Eg: placement news, cultural activities news, etc.

- Railway stations: to display the scheduling time of the train and the platform, the services offered by the railways.

- Hotels: to display the availability of the rooms and the room rents, the type of rooms.

- Restaurants: to display the menu and offers etc.

- Nursing homes: to display the staff attendance, the availability of the doctors, the list of the specialized doctors, no of in patients etc.

\section{CONCLUSION}

The above technical paper explains how we can develop as well as modify GSM based e-notice board. In addition to user can send the message for any location to the notice board. Fornew applications every time we need to write the manually message to the of text box. The target program could be GSM based home appliance, GSM based collage notice boardGSM based railway reservation, GSM based home security, and GSM based theatre ticket.

\section{REFERENCES}

[1] Books: GSM and Personal Communication-ones HandbookSiegmundRedl-MatthiasWeber Malcolm W.

[2] Books: Principles and Applications of GSM- Vijay Garg.

[3] http://www.edgefxkits.in/wireless-electronic-notice-board-using-gsm.

[4] http://extremeelectronics.co.in/avr-tutorials/getting-started

[5] Artificial Intelligence - Elain Rich \& Kevin Knight, Tata Mc Graw Hill, 2nd Edition. 